\title{
EFFECT OF VARIABILITY OF CURRENT INTENSITY (MILLIAMPERAGE) ON THE GRAY SCALE VALUES DRIVEN FROM CONE BEAM COMPUTED TOMOGRAPHIC IMAGES: AN IN-VITRO STUDY
}

\author{
Ahmed M. Abd Alsamad * and Sherouk Khalifa **
}

\begin{abstract}
Introduction: Cone beam computed tomography (CBCT) is an imaging modality of great value in dental field thanks to its lower radiation and high spatial resolution compared to Computed Tomography (CT). However there is still some controversy of using СBCT in bone density assessment. That is why this study was conducted to assess the ability of the gray scale values driven from $\mathrm{CBCT}$ by different milliamperage $(\mathrm{mA})$ settings to assess bone density.
\end{abstract}

Methodology: Seventeen mandibles were included in this study. On each mandible, a gutta percha marker was glued on the buccal surface of bone and another one on the same site on the lingual surface then covered by a layer of pink wax of thickness $13-17 \mathrm{~mm}$ to simulate soft tissue in patients imaging. The mandibles were fixed to their skulls and imaged by a CBCT machine Planmeca ProMax 3D Mid ${ }^{\circledR}$ with three different $\mathrm{mA}$ settings $(8,10$ and $12 \mathrm{~mA})$. For the resultant images, both corrected coronal images marked with gutta percha marker and others away from gutta percha marker were assessed and the measured gray scale values were tested for agreement between 3 scans.

Results: Changing of current intensity from $8 \mathrm{~mA}$ to $10 \mathrm{~mA}$ leads to a change of measured bone density by $24 \%$ in cuts away from radiopaque markers and $26 \%$ in cuts marked with radiopaque markers. Changing of current intensity from $8 \mathrm{~mA}$ to $12 \mathrm{~mA}$ leads to a change of measured bone density by at least $18 \%$ in cuts away from radiopaque markers and at least $21 \%$ in cuts marked with radiopaque markers. Bland-Altman limits of agreement show clinically poor agreements between the measured densities.

Conclusion: Changing of milliamprage (mA) setting from $8 \mathrm{~mA}$ to 10 or $12 \mathrm{~mA}$ will change the gray scale values denoting bone density in a statistically significant manner making bone density assessment from CBCT inaccurate.

KEYWORDS: Current intensity, milliamperage, mA, CBCT, Gray scale, Gray Values.

* Lecturer of Oral and Maxillofacial Radiology, Faculty of Dentistry, Cairo University.

** Assistant Professor of Oral and Maxillofacial Radiology, Faculty of Dentistry, Cairo University. 


\section{INTRODUCTION}

Nowadays Computed Tomography (CT) is an accepted medical practice that is considered as a gold standard for assessment of spongy and cortical bone quantitatively and qualitatively. However, high radiation dose that the patient receives as well as the high cost and the complexity act as limitation for its usage in dental practice ${ }^{(1-4)}$.

This raised the need for a new type of CT that can be used in dental field which is the Cone Beam Computed Tomography (CBCT) which is a less complex device of a lower cost and radiation as well as fast scanning and higher spatial resolution which increase its demand within the dental practitioners $^{(1-6)}$.

However it has been reported that CBCT has limitations related to higher noise and low contrast in comparison to conventional CT system as well as artifacts that arise from machine, software and patient factors such as hardening effect, scattered radiation, differences between scanners, changes in field of view (FOV), which result in incorrect gray scale levels that appears to be higher than normal $^{(1-4,6-7)}$.

With CBCT, the gray scale values of images are not absolute in comparison to Hounsfield unit (HU) assessed by CT as HU could be calibrated using the density values of water and air when the same density is scanned using different CT systems, which is not present in CBCT modality which depends on gray scale which are preset by the manufacturer of each machine ${ }^{(4,7)}$. Moreover CBCT values are affected by changes in the exposure parameters and size of FOV ${ }^{(3)}$. Thus this makes the values obtained from CBCT varies among different scanners while with CT values are stable ${ }^{(2,6)}$.

Although some studies have reported the utilization of CBCT for assessment of bone density ${ }^{(4,8-10)}$, others mentioned that this ability is questionable and that reliability of CBCT based mineral density measurement has not yet been totally accredited ${ }^{(2,6-7,11-13)}$ which indicates that more studies are needed to validate this reliability ${ }^{(5-6)}$.

That is why this study was conducted to assess the ability of the gray scale values driven from CBCT by different milliamperage ( $\mathrm{mA}$ ) settings to assess bone density.

\section{METHODOLOGY}

Seventeen mandibles were included in this study. The mandibles used in our study were collected from the Anatomy Department, Faculty of Medicine, Cairo University. The selected mandibles were free from any pathological lesions or fractures.

On each mandible, a gutta percha marker was glued on the buccal surface of bone and another one on the same site on the lingual surface. The mandibles with the glued markers were covered by a layer of pink wax of thickness $13-17 \mathrm{~mm}^{(14)}$ to simulate soft tissue in patients imaging.

The mandibles were fixed to their skulls using adhesive strips and then placed on the CBCT machine Planmeca Pro Max 3D Mid $^{\circledR}$ (Asentajankatu, Helsinki, Finland) in Oral and Maxillofacial Radiology Department at Faculty of Dentistry, Cairo University in a position resembling the clinical situation.

Each mandible fixed to its related skull was imaged three times using the following parameters: $90 \mathrm{kVp},(\varnothing 20 \mathrm{~cm} \times 10 \mathrm{~cm})$ field of view (FOV), resolution of $400 \mu \mathrm{m}$ voxel at an exposure time of 13.5 seconds and with 3 different $\mathrm{mA}$ settings 8,10 and 12 .

The resultant images were evaluated using Planmeca Romexis Viewer version 4.4.0.R (Asentajankatu, Helsinki, Finland). The slice thickness and slice gap were adjusted to be $0.4 \mathrm{~mm}$.

On the axial image, the first cut showing the buccal and lingual gutta percha markers from alveolar crest side was selected. Then the long axis of coronal cut on the axial image was aligned to pass through center of both buccal and lingual gutta percha markers. 
On the sagittal image, the long axis of coronal cut was aligned with the long axis of the buccal gutta percha marker.

A rectangle of known dimension was drawn on the corrected coronal image (marked with gutta percha marker) with its vertices on the bone border. The gray scale values denoting bone density inside the rectangle was measured (Figure 1A).

Then another corrected coronal cut was selected, away from the cut marked with the gutta percha by 5 cuts in distal direction ( 0.4 slice thickness $\mathrm{x} 5$ cuts $=2 \mathrm{~mm}$ ) but with the same alignment. A rectangle of known dimension was drawn on the corrected coronal image (away from gutta percha marker) with its vertices on the bone border. The gray scale values denoting bone density inside the rectangle was measured (Figure 1B).

The same steps were repeated with the scans of $8 \mathrm{~mA}, 10 \mathrm{~mA}$ and $12 \mathrm{~mA}$ settings. For both corrected coronal images marked with gutta percha marker and those away from gutta percha marker, the measured gray scale values were tested for agreement between 3 scans.

\section{Statistical Analysis}

1. Descriptive analyses:

Different measurements were described in terms of mean, standard deviation (SD), mean difference and SD difference.
2. Testing for normality:

To test for normality of the data, the ShapiroWilk test for normality was applied to choose the proper test for correlation and comparative analyses.

3. Assessing level of agreement between different CBCT bone density measurements (Normally distributed):

i) Mean absolute Difference

ii) Relative Mean absolute Difference = Mean Absolute Difference/Mean

iii) Dahlberg error and the relative Dahlberg error $(\mathrm{RDE})(\mathrm{RDE}=$ Dahlberg error $/$ Mean of reference measurement)

iv) Bland-Altman limits of agreement were used to demonstrate the level of agreement.

4. The significance level:

It was verified at $\mathrm{P}<0.05$. The results are considered to be statistically significant if $p$-value was less than 0.05 .

5. Statistical package used for this study:

The data of the measurements are tabulated using excel software (IBM Corporation, NY, USA) and IBM ${ }^{\circledR}$ SPSS $^{\circledR}$ Statistics Version 17 for Windows SPSS software (®SPSS, Inc., an IBM Company).

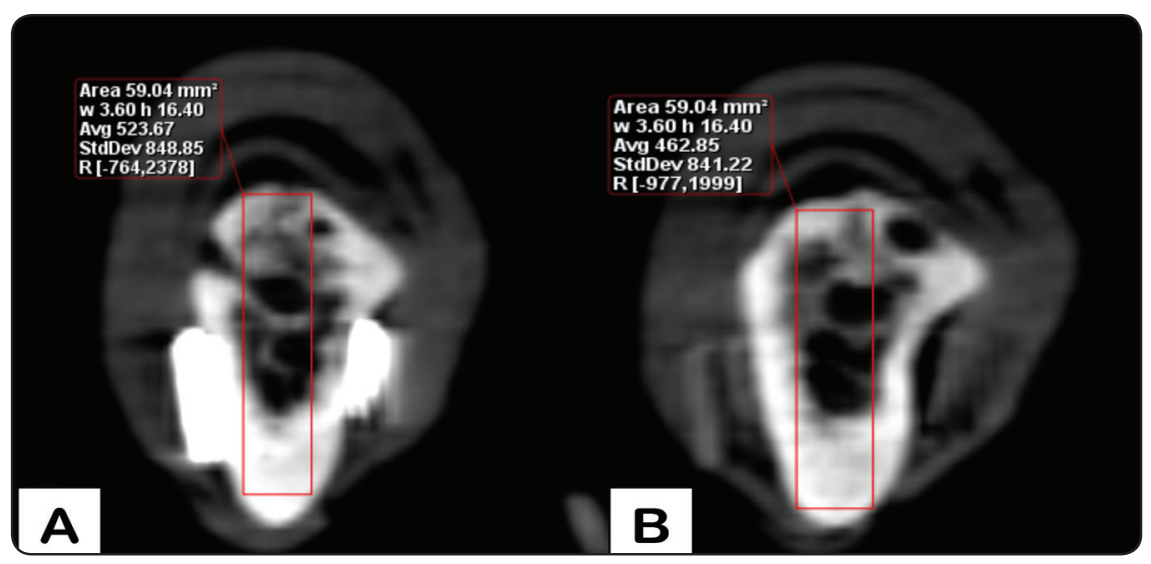

Fig. (1) (A) Rectangle of known dimension drawn on the corrected coronal image marked with the gutta percha marker with its vertices on the bone border. (B) Rectangle of known dimension drawn on the corrected coronal image away from the gutta percha marker. 


\section{RESULTS}

Comparing the effect of changing current intensity from $8 \mathrm{~mA}$ to $10 \mathrm{~mA}$ in CBCT on gray scale values denoting bone density assessment:

\section{In images marked with gutta percha markers:}

TABLE (1) Comparison of $10 \mathrm{~mA}$ measurement with $8 \mathrm{~mA}$ measurement in images marked with gutta percha markers

\begin{tabular}{|c|c|c|c|c|c|c|c|c|c|c|}
\hline & \multirow{2}{*}{ 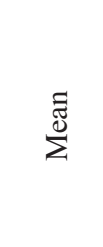 } & \multirow[t]{2}{*}{ हิ } & \multirow{2}{*}{ 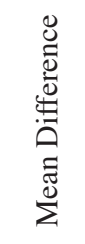 } & \multirow{2}{*}{ 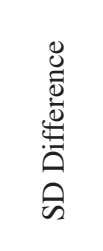 } & \multirow{2}{*}{ 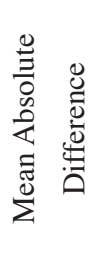 } & \multirow{2}{*}{ 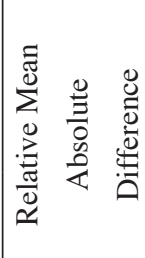 } & \multirow{2}{*}{ 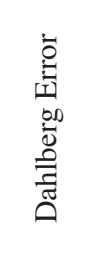 } & \multirow{2}{*}{ 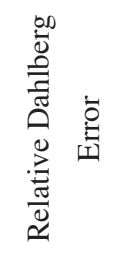 } & \multicolumn{2}{|c|}{$\begin{array}{l}\text { 95\% Confidence } \\
\text { of the Limits of } \\
\text { agreement }\end{array}$} \\
\hline & & & & & & & & & Lower & Upper \\
\hline $8 \mathrm{~mA}$ & 360.24 & 351.13 & \multirow{2}{*}{16.53} & \multirow{2}{*}{139.04} & \multirow{2}{*}{94.88} & \multirow{2}{*}{$26.34 \%$} & \multirow{2}{*}{96.10} & \multirow{2}{*}{$26.68 \%$} & \multirow{2}{*}{-256.00} & \multirow{2}{*}{289.06} \\
\hline $10 \mathrm{~mA}$ & 343.71 & 348.48 & & & & & & & & \\
\hline
\end{tabular}

In images away from gutta percha markers:

TABLE (2): Comparison of $10 \mathrm{~mA}$ measurement with $8 \mathrm{~mA}$ measurement in images away from gutta percha markers:

\begin{tabular}{|c|c|c|c|c|c|c|c|c|c|c|}
\hline & \multirow{2}{*}{ 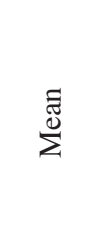 } & \multirow[t]{2}{*}{ ह } & \multirow{2}{*}{ 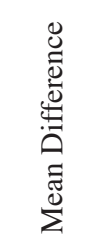 } & \multirow{2}{*}{ 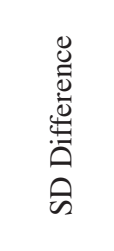 } & \multirow{2}{*}{ 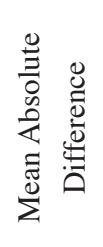 } & \multirow{2}{*}{ 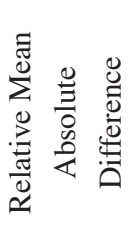 } & \multirow{2}{*}{ 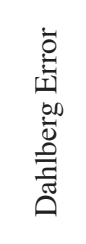 } & \multirow{2}{*}{ 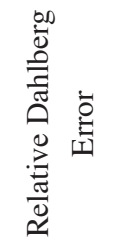 } & \multicolumn{2}{|c|}{$\begin{array}{c}\text { 95\% Confidence } \\
\text { of the Limits of } \\
\text { agreement }\end{array}$} \\
\hline & & & & & & & & & Lower & Upper \\
\hline $8 \mathrm{~mA}$ & 366.12 & 329.34 & & & & & & & & \\
\hline $10 \mathrm{~mA}$ & 37906 & 35473 & -12.94 & 127.69 & 91.18 & $24.90 \%$ & 88.07 & $24.05 \%$ & -263.21 & 237.33 \\
\hline
\end{tabular}

Changing of current intensity from $8 \mathrm{~mA}$ to $10 \mathrm{~mA}$ leads to a change of measured bone density by $24 \%$ in cuts away from radiopaque markers and $26 \%$ in cuts marked with radiopaque markers (Table $1 \& 2$ ).

Bland-Altman limits of agreement show clinically poor agreements between the measured densities.

Assessing of bone density in cuts away from radiopaque makers decreases the error by only $2 \%$ 


\section{Comparing the effect of changing current intensity from $8 \mathrm{~mA}$ to $12 \mathrm{~mA}$ in CBCT on gray scale values denoting bone density assessment:}

\section{In images marked with gutta percha markers:}

TABLE (3): Comparison of $12 \mathrm{~mA}$ measurement with $8 \mathrm{~mA}$ measurement in images marked with gutta percha markers

\begin{tabular}{|c|c|c|c|c|c|c|c|c|c|c|}
\hline & \multirow{2}{*}{$\sum^{\equiv}$} & \multirow{2}{*}{ क } & \multirow{2}{*}{ 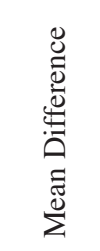 } & \multirow{2}{*}{ 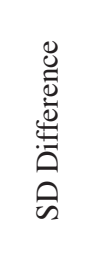 } & \multirow{2}{*}{ 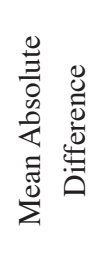 } & \multirow{2}{*}{ 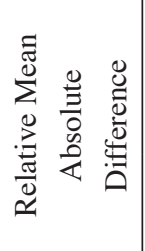 } & \multirow{2}{*}{ 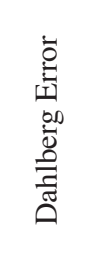 } & \multirow{2}{*}{ 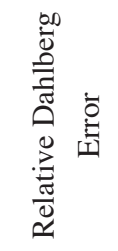 } & \multicolumn{2}{|c|}{$\begin{array}{l}\text { 95\% Confidence } \\
\text { of the Limits of } \\
\text { agreement }\end{array}$} \\
\hline & & & & & & & & & Lower & Upper \\
\hline $8 \mathrm{~mA}$ & 360.24 & 351.13 & \multirow{2}{*}{-31.65} & \multirow{2}{*}{106.61} & \multirow{2}{*}{87.18} & \multirow{2}{*}{$24.20 \%$} & \multirow{2}{*}{76.48} & \multirow{2}{*}{$21.23 \%$} & \multirow{2}{*}{-240.6} & \multirow{2}{*}{177.30} \\
\hline $12 \mathrm{~mA}$ & 391.88 & 342.05 & & & & & & & & \\
\hline
\end{tabular}

\section{In images away from gutta percha markers:}

TABLE (4): Comparison of $12 \mathrm{~mA}$ measurement with $8 \mathrm{~mA}$ measurement in images away from gutta percha markers:

\begin{tabular}{|c|c|c|c|c|c|c|c|c|c|c|}
\hline & $\sum^{\Xi}$ & है & 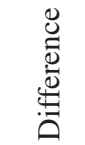 & 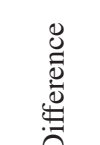 & 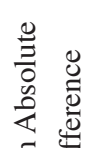 & 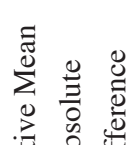 & 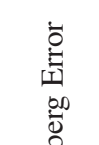 & 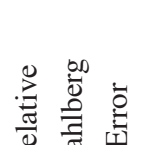 & \multicolumn{2}{|c|}{$\begin{array}{l}\text { 95\% Confidence } \\
\text { of the Limits of } \\
\text { agreement }\end{array}$} \\
\hline & & & $\sum^{\infty}$ & $\sqrt{2}$ & $\Sigma$ & & $\tilde{\Xi}$ & & Lower & Upper \\
\hline $8 \mathrm{~mA}$ & 366.12 & 329.34 & \multirow{2}{*}{16.53} & \multirow{2}{*}{98.82} & \multirow{2}{*}{79.24} & \multirow{2}{*}{$21.64 \%$} & \multirow{2}{*}{68.79} & \multirow{2}{*}{$18.79 \%$} & \multirow{2}{*}{-177.16} & \multirow{2}{*}{210.22} \\
\hline $12 \mathrm{~mA}$ & 349.59 & 341.01 & & & & & & & & \\
\hline
\end{tabular}

Changing of current intensity from $8 \mathrm{~mA}$ to $12 \mathrm{~mA}$ leads to a change of measured bone density by at least $18 \%$ in cuts away from radiopaque markers and at least $21 \%$ in cuts marked with radiopaque markers (Table 3\&4).

Bland-Altman limits of agreement show clinically poor agreements between the measured densities.

Assessing of bone density in cuts away from radiopaque makers decreases the error by only $2 \%$ 


\section{Comparing the effect of changing current intensity from $8 \mathrm{~mA}$ to $10 \mathrm{~mA}$ and $12 \mathrm{~mA}$ in CBCT on gray scale values denoting bone density assessment:}

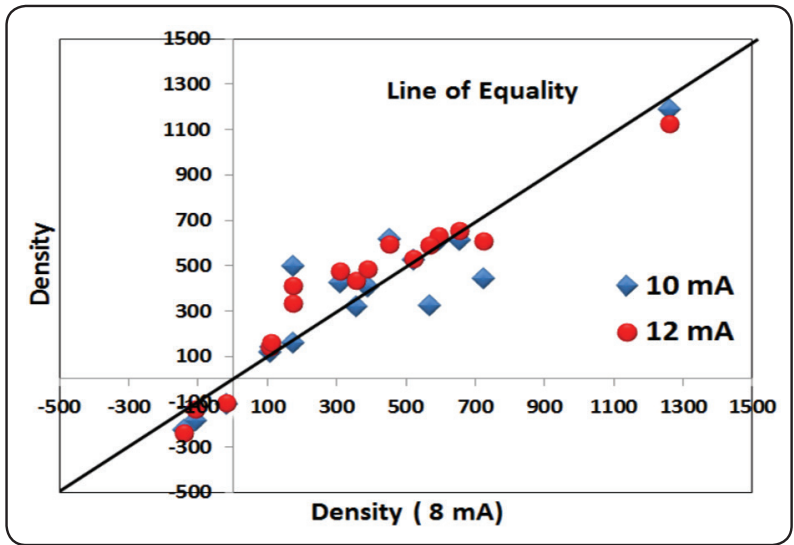

Fig. (2) Comparison of $10 \mathrm{~m} \mathrm{~A}$ and $12 \mathrm{~mA}$ measurement with $8 \mathrm{~mA}$ measurement in images marked with gutta percha markers

\section{DISCUSSION}

Accurate information on bone density is essential for proper establishment of surgical treatment plans. Several methods for preoperative assessment of the bone quality were proposed; most recently the helical CT and CBCT. Helical CT systems use HU for assessment of bone density which provides stable values. For CBCT, although it is a more recent technique, there is no such standard unit as in helical CT because the gray scale values of CBCT images are not absolute and varying according the CBCT device used ${ }^{(15-19)}$ and since it has been used instead of helical CT in many dental fields for assessment of hard tissues, it was mandatory to evaluate the validity of such application ${ }^{(6)}$.

The inadequacy of CBCT for assessment of bone density was reported by several authors. Oliveira et al ${ }^{(20)}$ stated that exposure parameters are highly varying between different CBCT units and thus affecting the calibration of gray values. Also, Pauwels et al (21) and Mah et al (22) mentioned that although CBCT devices are having images with similar scaling to $\mathrm{HU}$, the gray values are not

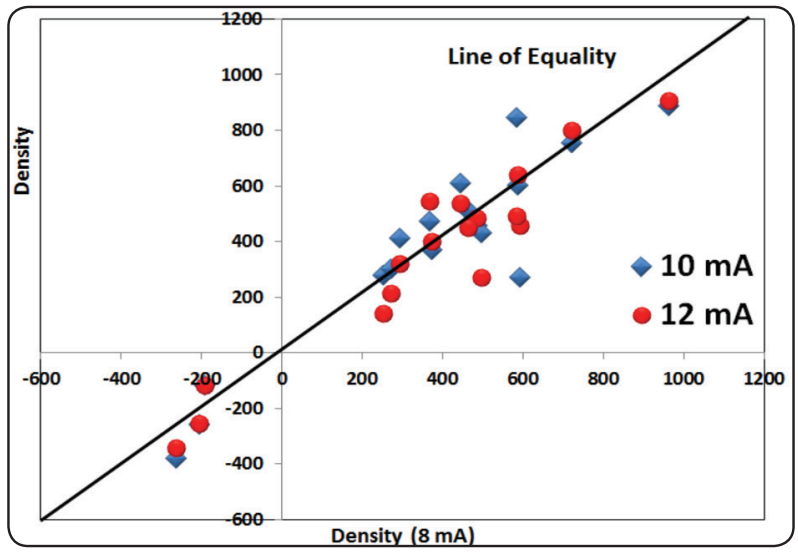

Fig. (3) Comparison of $10 \mathrm{~m} \mathrm{~A}$ and $12 \mathrm{~mA}$ measurement with $8 \mathrm{~mA}$ measurement in images away from gutta percha markers

precisely calculated because of the presence of great noise as well as the geometry of the device and the limited FOV. Moreover, the gray value for CBCT was found to be overestimated when compared with HU values from MSCT, which uses stable calibration. This was stated by Silva et al (6) who found that the measurements from both devices were not equivalent and that according to Nackaerts et al ${ }^{(19)}$ values from CBCT images were not accurate.

In accordance with the previous studies, the current study showed the inability of the CBCT to accurately measure bone density where it gave different gray values for the same areas scanned with different $\mathrm{mA}$ settings which was found to be up to $26 \%$ difference in measured density when changing the current intensity form $8 \mathrm{~mA}$ to $10 \mathrm{~mA}$ and up to $21 \%$ difference in measured density when $\mathrm{mA}$ was increased to $12 \mathrm{~mA}$ with poor agreement between the measured densities in different $\mathrm{mA}$ settings. Such variability of the gray values in CBCT as stated by Nackaerts et al ${ }^{(19)}$ resulted when density was assessed in different points of a homogeneous structure, where in the current study the density was measured at two close points. 
According to the results of this study, the use of CBCT for measuring gray values for assessment of the density of bony structures is not accepted. This comes with agreement of Silva et $\mathrm{al}^{(6)}$ who concluded that the reliability of $\mathrm{CBCT}$ for measuring bone density is absent and Pauwels et $\mathrm{al}^{(21)}$ who stated that any CBCT device will not be able to distinguish between different lesions based on gray values. They also stated the same when evaluating root lesions and the deposition of bone during healing. Similarly, Campos et al ${ }^{(2)}$ mentioned that based on the available researches, CBCT should not be used as the examination of choice for assessment of the density of mineralized structures. Moreover, Oliveira et $\mathrm{al}^{(20)}$ reported that the effect of $\mathrm{mA}$, which varies between FOVs within the same machine, also adds to the inaccurate gray values from $\mathrm{CBCT}$ images.

It was suggested by Mah et al ${ }^{(22)}$ and Reeves et $\mathrm{al}^{(23)}$ that HU calibration is mandatory in order to result in a stable density value when the structure is scanned using different CBCT systems. However, the CBCT based HU measurement still remains questionable ${ }^{(24-25)}$ and without such system, it is difficult to reach consistent gray levels resulting from different machines.

Based on such proven inaccuracy of the gray scale values from $\mathrm{CBCT}^{(20)}$, it was concluded that the ability of CBCT to provide assessment of bone is limited. Without HU it can be difficult to analyze bone quality ${ }^{(22)}$.

\section{CONCLUSION}

Changing of $\mathrm{mA}$ settings will change the gray scale values denoting bone density in a statistically significant manner making bone density assessment from CBCT inaccurate. Presence of gutta percha marker in CBCT images has a minor effect on the measured gray scale values.

\section{REFERENCES}

1- Song YD, Jun SH, Kwon JJ: Correlation between bone quality evaluated by Cone-Beam Computerized Tomography and implant primary stability. Int $\mathrm{J}$ Oral Maxillofac Implants. 2009 Jan-Feb; 24(1):59-64.

2- Campos MJ, de Souza TS, Mota Júnior SL, Fraga MR, Vitral RW: Bone mineral density in cone beam computed tomography: Only a few shades of gray. World J Radiol. 2014 Aug 28; 6(8):607-12.

3- Varshowsaz M, Goorang S, Ehsani S, Azizi Z, Rahimian S: Comparison of tissue density in Hounsfield Units in Computed Tomography and Cone Beam Computed Tomography. J Dent (Tehran). 2016 Mar; 13 (2):108-115.

4- Cassetta M1, Stefanelli LV, Pacifici A, Pacifici L, Barbato E: How accurate is CBCT in measuring bone density? A comparative CBCT-CT in vitro study. Clin Implant Dent Relat Res. 2014 Aug; 16(4):471-8.

5- Güngör E, Yildirim D, Çevik R: Evaluation of osteoporosis in jaw bones using cone beam CT and dual-energy X-ray absorptiometry. J Oral Sci. 2016; 58(2):185-94.

6- Silva IM, Freitas DQ, Ambrosano GM, Bóscolo FN, Almeida SM: Bone density: comparative evaluationof Hounsfield units in multislice and cone-beam computed tomography Braz Oral Res. 2012 Nov-Dec; 26(6):550-6.

7- Kim DG: Can Dental Cone Beam Computed Tomography Assess Bone Mineral Density? J Bone Metab. 2014 May; 21(2):117-26.

8- Valiyaparambil JV, Yamany I, Ortiz D, Shafer DM, Pendrys D, Freilich M, Mallya SM: Bone quality evaluation: comparison of cone beam computed tomography andsubjective surgical assessment. Int J Oral Maxillofac Implants. 2012 Sep-Oct; 27(5):1271-7.

9- Song YD, Jun SH, Kwon JJ: Correlations between bone qualities evaluated by cone beam computerized tomography and implant primary stability. Int $\mathrm{J}$ Oral Maxillofac Implants. 2009 Jan-Feb; 24(1):59-64.

10- Aranyarachkul P, Caruso J, Gantes B, Schulz E, Riggs M, Dus I, Yamada JM, Crigger M: Bone density assessment of dental implant sites: 2. Quantitative cone beam computerized tomography. Int J Oral Maxillofac Implants. 2005 May-Jun; 20(3):416-24.

11- Sarkis A, Noujeim M, Nummikoski P: Bone density measurements in cone-beam computed tomography. Oral Surg. Oral Med. Oral Pathol. 2007 Feb 28; 103(2):e53. 
12- Scarfe WC, Farman AG: Interpreting CBCT Images for implant assessment: Part 1-Pitfalls in image interpretation. Australas Dent Pract. 2010 July-August; 20:106-14.

13- Shintaku WH, Venturin JS, Azevedo B, Noujeim M: Application of cone beam computed tomography in fractures of the maxillofacial complex. Dent Traumatol. 2009 Aug; 25(4):358-66.

14- Schropp L, Alyass N S, Wenzel A, and Stavropoulos A: Validity of wax and acrylic as soft-tissue simulation materials used in in vitro radiographic studies. Dentomaxillofacial Radiology. 2012; 41(8), pp. 686-690.

15- Turkyilmaz I, Ozan O, Yilmaz B, Ersoy AE: Determination of bone quality of 3 implant recipient sites using Hounsfield Unit from computerized tomography: a clinical study. Clin Implant Dent Res 2008; 10: 238-244.

16- Isoda K, Ayukawa Y, Tsukiyama Y, Sogo M, Matsushita Y, Koyano K: Relationship between the bone density estimated by cone-beam computed tomography and the primary stability of dental implants. Clin Oral Implants Res. 2012 Jul; 23(7):832-6.

17- Arisan V, Karabuda ZC, Avsever H, Özdemir T: Conventional multi-slice computed tomography (CT) and cone-beam CT (CBCT) for computer- assisted implant placement. Part I: relationship of radiographic gray density and implant stability. Clin Implant Dent Relat Res 2013 Dec; 15(6):893-906

18- Bilhan H, Arat S, Geckili O: How Precise Is Dental Volumetric Tomography in the Prediction of Bone Density? Int J Dent. 2012; 348908. Epub 2012 May 30.
19- Nackaerts O, Maes F, Yan H, Couto Souza P, Pauwels R, Jacobs R: Analysis of intensity variability in multislice and cone beam computed tomography. Clin Oral Implants Res. 2011 Aug; 22(8):873-9.

20- Oliveira ML, Tosoni GM, Lindsey DH, Mendoza K, Tetradis S, Mallya SM: Influence of anatomical location on CT numbers in cone beam computed tomography. Oral Surg Oral Med Oral Pathol Oral Radiol. 2013 Apr; 115(4):558-64.

21- Pauwels R, Nackaerts O, Bellaiche N, Stamatakis H, Tsiklakis K, Walker A, Bosmans H, Bogaerts R, Jacobs R, Horner K: SEDENTEXCT Project Consortium. Variability of dental cone beam CT grey values for density estimations. Br J Radiol. 2013 Jan; 86(1021):20120135.

22- Mah P, Reeves TE, McDavid WD: Deriving Hounsfield units using grey levels in cone beam computed tomography. Dentomaxillofac Radiol. 2010 Sep; 39(6):323-35.

23- Reeves TE, Mah P, McDavid WD. Deriving Hounsfield units using grey levels in cone beam CT: a clinical application. Dentomaxillofac Radiol 2012; 41:500-8.

24- Molteni R: Prospects and challenges of rendering tissue density in Hounsfield units for cone beam computed tomography. Oral Surg Oral Med Oral Pathol Oral Radiol 2013; 116:105-19.

25- Schulze R, Heil U, Gross D, Bruellmann DD, Dranischnikow E, Schwanecke U, Schoemer E: Artefacts in CBCT: a review. Dentomaxillofac Radiol 2011; 40:265-73. 